\title{
School peer victimization of young people with craniofacial conditions: A comparative study
}

\author{
PAM CARROLL ${ }^{1} \&$ ROSALYN SHUTE ${ }^{2}$ \\ ${ }^{1}$ School of Psychology, Flinders University, South Australia, and ${ }^{2}$ University of Ballarat, Victoria, \\ Australia
}

\begin{abstract}
Young people with and without craniofacial conditions were compared on perceived incidence and frequency of school-based peer victimization and resultant distress; the relationship of craniofacial disfigurement severity to victimization incidence and frequency was also assessed. A deliberately biased sample-over-representing greater disfigurement-of 85 young people (9 to 16 years of age), continuing or having completed treatment for a craniofacial condition, were rated on current disfigurement severity, and responded to an extended version of the Direct and Indirect Aggression Scale (DIAS) presented as a structured telephone interview. Fifty-five matched school peers without craniofacial conditions responded to the same interview. Greater craniofacial disfigurement was associated with greater likelihood and frequency of being targeted with certain aggressive behaviours identified from the craniofacial literature. However, no more young people with, than without, craniofacial conditions experienced frequent victimization, considerable emotional distress or references to their appearance. This study provides a social comparison for victimized young people with craniofacial conditions. Knowing that those without disfigurement are also victimized may help ease their disfigurement-related cognitions. This study highlights the limitations of surgical correction for disfigurement, and promotes a more realistic view for victimization experiences and intervention options.
\end{abstract}

Keywords: Craniofacial, Direct and Indirect Aggression Scale (DIAS), emotional distress, facial disfigurement, victimization

\section{Introduction}

The victimization experiences that young people with craniofacial conditions might suffer at the hands of their school peers is an issue of concern for the individuals, their parents and medical staff alike. All are keen to minimize, even avoid, such experiences. While reconstructive surgery to 'normalize' their appearance (over and above surgery that is functionally imperative) is the primary habilitation/rehabilitation method used to address this issue (Lefebvre \& Munro, 1978; Marsh, 1995; Munro, 1995; Tan \& Pigott, 1993), psychosocial methods-including social skills and assertiveness training-are also possible (Gerrard, 1991; Kish \& Lansdown, 2000; MacGregor, 1990). To help inform victimization intervention choices, there is a basic question that warrants clarification. Are young people with craniofacial disfigurements at greater risk of experiencing school peer victimization than 
those in the general population? While it is assumed that their disfigurement places them at greater risk (La Greca, 1990; Vessey, Swanson \& Hagedorn, 1995), this question has not been adequately empirically addressed. Such normative information may place the importance of surgical correction into greater perspective given that surgery involves medical risk, financial burden, personal pain and psychological morbidity yet may not ultimately offer complete normalization of appearance (Munro, 1995). Normative information may also help young people with disfigurements avoid overly attributing victimization experiences to their disfigurement (Changing Faces, 2000; Kish, 1998b; Kish, 1998c) and thus possibly help them to maintain closer peer social relations.

Peer victimization may be viewed as the experience of being targeted with some form of aggression. Being a target of aggression is a common experience for people with disfigurements (Bradbury, 1996; Changing Faces, 2000; Kish, 1998c; Macgregor, 1990). According to the craniofacial literature, there is a range of behaviours that they frequently experience (Macgregor, Abel, Brynt, Lauer, \& Weissmann, 1953), including being stared at, asked personal questions, and having others standing further away than is normal. While these behaviours may not be intrinsically aggressive, nor specifically intended so by the performer, it is understandable that an individual with a disfigurement may perceive these behaviours as being hostile. Young people with craniofacial conditions also commonly report being teased (Gerrard, 1991). Teasing is frequently equated with verbal comments and name-calling. Teasing is a somewhat ambiguous form of aggression. It can be humorous and fun (Pawluk, 1989; Shapiro, Baumeister \& Kessler, 1991) and even serve to strengthen relationships (Keltner, 1998 \& 2001; Kowalski, 2000); however, this depends on the recipient's perspective. For the majority of children and teenagers alike, regardless of the performer's intention, teasing is commonly perceived as an aggressive act and causes emotional distress (Shapiro et al., 1991) even though young people begin to understand and use the pro-social aspects of teasing more by the ages of 11-12 years (Keltner, Capps, Kring, Young \& Heerey, 2001).

Aggression research within the general population has traditionally focused on physical and verbal behaviours (e.g., kicking, yelling, name calling). Males have been depicted as being the main perpetrators (see review by Eagly \& Steffen, 1986). However, more recent research has emphasized the use of indirect forms of aggression (e.g., ignoring and excluding others, spreading false stories) that are more typical of females (e.g., Crick, Nelson, Morales, Cullerton-Sen, Casas, \& Hickman, 2001). While boys surpass girls in using direct forms of aggression, teenage girls surpass teenage boys in using indirect aggression (Owens, 1996). Further, research indicates that victimization is a common problem, with 20 to $25 \%$ of young people in the general population experiencing some form of aggression at least weekly (e.g., Rigby, 1996). In addition, victims of all forms of aggression suffer more anxiety and depression than non-victims (Crick \& Bigbee, 1998; Slee, 1994; Slee, 1995).

The Direct and Indirect Aggression Scale (DIAS), comprising three subscales-Direct Physical, Direct Verbal \& Indirect Aggression-corresponding to the aforementioned forms of aggression (Bjorkqvist, Osterman \& Lagerspetz, 1994) is a measure that has been developed, over numerous studies using item and factor analysis, for use with the general population. However, with the exception of teasing, the DIAS does not include the aggressive behaviours commonly experienced by those with craniofacial conditions, such as being stared and pointed at, and asked personal questions. These behaviours, which have been gleaned from the craniofacial literature (Bradbury, 1996; Changing Faces, 2000; Gerrard, 1991; Kish, 1998c; Macgregor, 1990; Macgregor, Abel, Brynt, Lauer, \& Weissmann, 1953), have been added to the DIAS for the purpose of the current study and grouped under the title of 'craniofacial aggression', although we do not 
mean to imply that these behaviours are uniquely experienced by those with craniofacial conditions. Rather, the literature suggests that they are especially salient for this population. The DIAS is a convenient measure to use for this comparative study since it has been so widely used with the general population (in countries including Finland, Israel, Poland, Italy \& Australia), and the additional items may render it also suitable for use with a craniofacial population. Further, by asking respondents about the content of some DIAS items, such as name-calling and yelling (i.e. did the name-calling/yelling refer to your intelligence, sporting ability or appearance?), appearance-based victimization could be more adequately explored for both groups. As for young people with craniofacial disfigurements, appearance is commonly the subject of aggression among the general population (Cash, 1995; Crozier \& Dimmock, 1999; Kowalski, 2000; Roth, Coles \& Heimberg, 2002; Shaw, Meek \& Jones, 1980), across age groups (Shapiro, 1991). In a study of British 15 year olds in the general population, $75 \%$ reported being distressed by teasing about appearance (Lovegrove, 2003).

There is only one published paper (Broder, Smith \& Strauss, 2001) in which the victimization experiences of young people with and without craniofacial conditions have been compared. That paper reported data for 99 kindergarten to grade 12 children (48 girls, 52 boys) with craniofacial conditions. Most (66\%) had a cleft lip and/or palate, 33\% had multiple defects or other craniofacial deformities, $66 \%$ were from regular or gifted classes and $33 \%$ were in special classes for children with cognitive deficiencies. Children were matched with classmates without craniofacial conditions on race, gender, intellectual status and general socio-economic status and were compared on whether they were 'teased by others about speech' or 'teased by others about appearance'. Results were based on teachers' reports and showed that children with craniofacial conditions in exceptional classes were teased more than their matched peers about speech and appearance. However, contrary to prediction and to the widely held assumption that those with craniofacial conditions are teased more, children with craniofacial conditions in regular classes experienced no more teasing than matched peers. In another paper (Dawkins, 1996), young paediatric outpatients aged between 8 and 16 years with, and without, conditions affecting their appearance were compared in terms of being subjected to bullying. Victimization was found to be no more likely for those with a visible disability. There are no studies in which the experiences of young people with and without craniofacial conditions have been compared using the currently acknowledged range of aggressive behaviours - direct physical and verbal, and indirect-and using young people's own report. Self-report is important to use as some forms of aggression such as looks and gestures are subtle or covert and teachers are rarely aware of them (Shute, Owens \& Slee, 2002).

The present study identified a group of school age young people, with varying degrees of craniofacial disfigurement, for which surgical treatment was either complete, in progress or contemplated. The aim of the study was to compare their experiences of school peer victimization and associated emotional distress with those of young people without craniofacial conditions. A further aim was to explore the relationship of craniofacial disfigurement severity to the incidence and frequency of victimization. Based on the widely held assumption that craniofacial disfigurement would be associated with victimization, we hypothesized that, for young people with craniofacial conditions, compared to those without: a) a greater proportion would experience peer victimization; b) they would experience victimization more frequently; c) they would be more emotionally distressed by their victimization. We also hypothesized for those with craniofacial conditions that $d$ ) greater facial disfigurement would predict a greater incidence and frequency of victimization. 


\section{Method}

\section{Participants}

One hundred and forty young people participated in this study, 85 (44 males, 41 females) ranging in age from 9 to 16 years (mean $=12.70$ years, $S D=1.97$ ) with craniofacial conditions, and 55 (28 males, 27 females) ranging in age from 9 to 16 years (mean $=12.76$ years, $\mathrm{SD}=2.05$ ) with no craniofacial conditions, who acted as controls. No matched controls were obtained for 30 of those with craniofacial conditions. Reasons for this included time constraints for school principals and controls declining to participate. The unmatched craniofacial participants were included only in disfigurement severity analyses. All participants and their parents spoke English.

Craniofacial group. Young people with craniofacial conditions living in metropolitan or country South Australia were recruited through the Australian Craniofacial Unit at the Women's and Children's Hospital in Adelaide. They were considered for the study only if they were contactable, had current clinical facial photographs on file and had previously consented to research involvement. Those with an intellectual disability were excluded in order to maintain participant self-report reliability.

To enhance disfigurement severity as a focus, the study was biased towards including young people with more severe facial disfigurement. All those with major syndromes (e.g., Turners, Noonan, Nagar, Goldenhar) and all those whose visual disfigurement was less amenable to surgical correction (e.g., dysplastic ear, eye tumor, anophthalmia) were contacted. Of those conditions where visual disfigurement was more amenable to early surgical correction, only the three most visually disfigured in each category of condition (injuries, masses, conditions affecting head shape, conditions affecting facial symmetry, malocclusion, cleft lip and/or palate) were contacted.

Study information and consent forms were posted to the selected families. One week later, this was followed by a phone call so that any questions could be answered. Verbal and signed consent were obtained from parents and participants for the researcher to conduct a $15-20$ minute telephone interview with the young person and to contact their school principal, as approved by the University and Hospital ethics committees, and the relevant educational bodies.

One hundred and twelve young people with craniofacial conditions were contacted and $68 \%$ of them participated. Twenty-seven declined outright and eight declined for reasons including: no longer at school; in other studies; parents refused; not prepared for the school principal to know of their condition. Many non-participants were aged between 12 and 13 years, the age when Australian children transition from primary to high school. The final sample used for the comparative analyses comprised $13 \%$ with no visible disfigurement, $25 \%$ with slight, $35 \%$ with slight-moderate, $22 \%$ with moderate-severe and $5 \%$ with severe disfigurement.

Control group. Young people to act as controls were recruited using school principals who were provided with strict selection criteria. Principals were instructed to select two young people without craniofacial conditions, who were matched with the young person with a craniofacial condition for school class, gender, and academic achievement, and were closest in age. These criteria were discussed with principals and provided in writing, so there is good reason to believe that the control children were chosen accordingly and that the sample was not biased towards those suffering greater victimization. Principals posted information and consent forms to the selected families who were given the same information as those 
with craniofacial conditions, with the exception that there was no mention of the study interest in craniofacial conditions. This was to avoid further stigmatizing the classmate with the condition.

Those willing to participate posted their contact details to the researcher. Verbal and signed consent were obtained as for the craniofacial group. If two young people from any one class responded, only the response from the one closest in age was used in the final analysis.

\section{Measurement of victimization}

The incidence and frequency of victimization and the degree of resultant emotional distress were measured using an adapted version of the Direct and Indirect Aggression Scale (DIAS), (Bjorkqvist, Osterman \& Lagerspetz, 1994). This comprised the original 24 selfreport DIAS items over three subscales of aggressive behaviour:

1. Direct Physical Aggression: Hit, kick, trip, push, take things, shove and pull.

2. Direct Verbal Aggression: Yell, call you names, insult, tease, and say they are going to hurt you.

3. Indirect Aggression: Say bad things behind your back, tell false stories about you, shut you out of the group, say to others 'let's not be with them', write nasty notes about you, criticize your hair or clothing, become friends with others as revenge, tell your secrets to others, gossip, ignore, try to get others to dislike you, plan secretly to bother you.

The original DIAS instructions requested young people to rate, using a five point Likert scale from 0 (never) to 4 (very often), how frequently individual peers perpetrated each aggressive behaviour. However, to comply with ethical standards, Owens (1996) modified this rating to students' estimations of aggression frequencies within year levels, rather than referring to individual peers. For the current study, ratings were further modified to indicate the individual's perceived frequency of experiencing each aggressive behaviour at school in the current year, following Walsh (1998).

We also added four measures to explore issues for the craniofacial population that are not currently addressed in the general aggression literature. We added:

1. The group of behaviours gleaned from the craniofacial literature and entitled craniofacial aggression. These are: pinch, point, stare, stand further away than usual, impersonate (make a face, talk or move like you), laugh, snigger, make jokes about you, make fun by repeating what you say, asking personal questions.

2. A measure of emotional distress associated with each aggressive behaviour, with a five point Likert scale from 0 (not upset) to 4 (very upset).

3. A request for the specific content of some behaviours-yell, call names, insult, impersonate, say bad things behind your back, tell false stories about you, gossip, make jokes, ask personal questions, in order to explore the subject of appearance-based victimization.

4. A final item-Do kids say or do some nice things to you? - so that the questionnaire ended on a positive note.

This adapted scale contained 34 items and was used as a structured telephone interview conducted by the first author. 
Reliability of the Direct and Indirect Aggression Scale. The three DIAS subscales-Physical, Verbal, and Indirect Aggression - had good internal consistency reliability, with Cronbach's alphas of .85, .76, .85 respectively. These compared favourably with priorly reported Cronbach's alphas for the DIAS subscales that ranged between .80 and .94 'for most samples' (Bjorkqvist et al, 1994), from .78 to .96 (Owens, 1996) and were .85, .75 and .94 for Physical, Verbal and Indirect Aggression respectively in Walsh's (1998) study.

The 10 added craniofacial aggression items also proved to be a coherent group of behaviours with a Cronbach's alpha of .76, indicating good internal consistency reliability.

Factor analysis of the Direct and Indirect Aggression Scale. Since, in this study, the DIAS was used with a craniofacial population for the first time, Bjorkqvist et al's. (1994) three-factor structure of the original 24 items was checked for robustness with this population, using Principal Axis Factoring with Varimax rotation. While the results should be treated with caution since the sample size to item ratio was smaller than is recommended for factor analysis (Pallant, 2001), the item inter-correlations were adequate for factor analysis and the 24 items largely grouped into the expected three factors.

\section{Measurement of content of aggression}

Requesting participants to reveal the content of aggression was preceded by the first author acknowledging the very personal nature of these questions and suggesting that they should answer only if happy to do so. Participants were assured it was perfectly acceptable to say, 'I would rather not say'. If this was their response, they were further asked if it was possible to answer the question by choosing from the following alternatives: 'about my intelligence', 'about the way I play sport', 'about my friends', 'about the way I look', 'something else' or 'I would rather not say'.

\section{Measurement of facial disfigurement}

For participants with craniofacial conditions, a score for disfigurement was obtained by having the researcher, and a clinician from the craniofacial unit, rate frontal and profile photographs for disfigurement severity using a five point Likert scale ranging from 0 (no facial disfigurement) to 4 (severe facial disfigurement). This method has been used extensively with individuals with cleft lip and palate (e.g., Richman \& Millard, 1997), with intra-class correlation coefficients of between 0.79 and 0.84 reported. For the current study, the inter-rater correlation was .89.

\section{Results}

Non-parametric statistical analyses were used throughout as the score distributions were an inverse J shape and non-transformable. The results are presented as medians and interquartile ranges. Difference scores from the matched case-control pairs were analyzed using Multinomial Logistic Regression (using SPSS version 11 for Windows) with reporting of the odds ratios (OR). These are the scores being reported on unless otherwise stated.

\section{Incidence of frequent aggression}

Being teased and called names were the behaviors most commonly experienced by young people in both groups. Table I shows the percentage experiencing each aggressive behaviour 
Table I. Experience of aggression and a positive occurrence, at least weekly, for the craniofacial and control group ${ }^{\dagger}$.

Craniofacial group
$n=55$

(\%)
Control group

$N=55$

(\%)

Physical aggression

Take

\section{9}

7.1

Pull

Kick

Push

Shove

Hit

Verbal aggression

Tease

Yell

Names

Insult

Threaten

Indirect aggression

Ignore

Dislike

Shut

Stories

Bad things

Revenge

Lets not

Notes

Criticize

Secrets

Gossip

Bother

Craniofacial aggression

Point

Stare

Impersonate

Laugh

Joke

Fun

Pinch

Snigger

Questions

Away

Positive experience

Nice things
7.1

5.4

17.9

7.1

5.4

21.4

10.7

23.2

7.1

7.1

16.5

12.5

16.1

8.9

12.5

3.6

8.9

1.8

7.1

3.6

3.6

0.0

10.7

12.5

17.9

12.5

3.6

10.7

1.8

10.7

3.6

8.9

82.1
1.8

14.3

14.3

5.4

10.7

10.7

10.7

23.2

16.1

28.6

14.3

3.6

10.7

7.1

14.3

3.6

12.5

1.8

8.9

0.0

3.6

7.1

0.0

0.0

3.6

8.9

7.1

7.1

3.6

8.9

3.6

5.4

1.8

0.0

80.4

frequently_weekly/almost daily. Approximately $20-30 \%$ were frequently teased and called names. It is of interest to note that those in the control group also experienced most of the behaviours commonly reported by those with craniofacial conditions, for example being stared at, made fun of, laughed at and impersonated.

Using a one-sided Fisher's Exact test of independence and 95\% confidence level, no statistically significant larger proportion of the craniofacial compared with the control group experienced frequent physical, verbal, indirect or craniofacial aggression (Table II). Given 
Table II. Incidence of frequent aggression and considerable distress $\uparrow$, for the craniofacial and control group.

\begin{tabular}{lccc}
\hline & Craniofacial group & Control group \\
& $n=55$ & $n=55$ & $p^{*}$ \\
\hline & $(\%)$ & $(\%)$ & 0.50 \\
Physical & & Frequent aggression & 0.39 \\
Verbal & 25 & 27 & 0.31 \\
Indirect & 36 & 40 & 0.38 \\
Craniofacial & 43 & 36 & 0.32 \\
Physical & 41 & 36 & 0.38 \\
Verbal & 23 & 18 & $0.05^{\dagger \dagger}$ \\
Indirect & 41 & 53 & 0.36 \\
Craniofacial & 36 & 27 & 53 \\
\hline
\end{tabular}

$\dagger$ figures presented as percentages.

*using Fisher's Exact test (one-sided).

$\dagger \dagger$ inon significant-opposite to predicted direction.

$n=55$ matched pairs, this analysis had sufficient power (85\%) to detect a small effect size (Cohen, 1988). Therefore, contrary to prediction, young people with craniofacial conditions, as a group, were no more likely to be frequently aggressed against. In both groups, approximately $25 \%$ experienced frequent physical aggression and about $40 \%$ experienced frequent verbal, indirect and craniofacial aggression.

Relationship of disfigurement severity to the incidence of aggression. The full sample $(n=85)$ of those with craniofacial conditions was used to assess whether facial disfigurement severity was associated with weekly/almost daily aggression. Using one-sided Fisher's Exact tests with $95 \%$ confidence levels, no relationship was found between disfigurement severity and frequent physical or indirect aggression. However, disfigurement severity had a statistically significant relationship with frequent craniofacial aggression, Fisher's Exact (4, $n=85)=13.96, p<.01$, and frequent verbal aggression, Fisher's Exact $(4, n=85)=8.74$, $p<.05$. Further, those with moderate-severe, but not severe, disfigurement were particularly likely to experience frequent verbal aggression. With $n=85$, this test had sufficient power $(83 \%)$ to detect a small-medium effect size (Cohen, 1988). Within the craniofacial group, therefore, it was those with more severe disfigurement who were more likely targets of frequent craniofacial and verbal aggression.

\section{Incidence of considerable distress}

It can also be seen in Table II that, using a one-sided Fisher's Exact test of independence and $95 \%$ confidence level, the proportion of young people being quite/very upset owing to physical, verbal, indirect or craniofacial aggression was statistically not significantly greater for those with than without craniofacial conditions. Therefore, young people with craniofacial conditions were not distressed by aggression in greater numbers.

\section{Incidence of appearance related comments and impersonations}

For those with and without craniofacial conditions, $36 \%$ and $27 \%$, respectively, reported experiencing references to their appearance. Using a one-sided Fisher's Exact test and 95\% 
confidence level, this difference was not statistically significant. Further, similar proportions in both groups preferred not to comment on the content of remarks and impersonations directed at them.

\section{Frequency of aggression}

Multinomial logistic regression was used to test between group differences in aggression frequency (Table III). It was found that, together, physical, verbal, indirect and craniofacial aggression reliably distinguished between groups, $\chi^{2}(4, n=54)=10.01, p<0.04$ with $13 \%$ of the between group variance accounted for (McFadden's rho = .13). However, craniofacial aggression was the only variable, in isolation, to significantly distinguish between groups. Consistent with our hypothesis, the odds ratio of 3.38 indicated that young people scoring 1 standard deviation higher on craniofacial aggression were greater than 3 times more likely than lower scoring individuals to have a craniofacial condition. Therefore, as hypothesised, young people with craniofacial conditions experienced craniofacial aggression more frequently than those without; however, contrary to our hypothesis, they experienced physical, verbal and indirect aggression, as measured by the DIAS, with comparable frequency.

In the absence of a formula to estimate power for matched sample multinomial logistic regression, we used the formula for regression suggested by Tabachnick and Fidell (1996),

Table III. Frequency of aggression and distress for the craniofacial and control group ${ }^{\dagger}$, and odds ratios and confidence intervals for between group differences in aggression frequency, distress, and distress due to craniofacial aggression after accounting for frequency.

\begin{tabular}{|c|c|c|c|c|}
\hline & $\begin{array}{c}\text { Craniofacial group } \\
n=55 \\
\text { Median (IQR) }\end{array}$ & $\begin{array}{l}\text { Control group } \\
\quad n=55 \\
\text { Median (IQR) }\end{array}$ & OR $(95 \% \mathrm{CI})$ & $P^{*}$ \\
\hline \multicolumn{5}{|c|}{ Aggression frequency } \\
\hline Physical & $0.00(0.00,0.93)$ & $0.14(0.00,0.57)$ & $0.61(0.27-1.40)$ & 0.24 \\
\hline Verbal & $0.80(0.00,1.35)$ & $0.60(0.00,1.60)$ & $0.61(0.28-1.37)$ & 0.23 \\
\hline Indirect & $0.25(0.02,0.75)$ & $0.33(0.08,0.67)$ & $0.94(0.48-1.85)$ & 0.85 \\
\hline Craniofacial & $0.40(0.10,1.08)$ & $0.30(0.10,0.50)$ & $3.38(1.30-8.76)$ & 0.01 \\
\hline \multicolumn{5}{|c|}{ Distress due to aggression } \\
\hline Physical & $0.00(0.00,0.57)$ & $0.14(0.00,0.43)$ & $1.63(0.38-7.07)$ & 0.51 \\
\hline Verbal & $0.60(0.00,1.40)$ & $0.40(0.00,1.60)$ & $0.42(0.13-1.34)$ & 0.14 \\
\hline Indirect & $0.17(0.00,0.88)$ & $0.42(0.08,0.83)$ & $0.50(0.23-1.08)$ & 0.08 \\
\hline Craniofacial & $0.10(0.00,0.90)$ & $0.10(0.00,0.50)$ & $5.68(1.55-20.89)$ & 0.01 \\
\hline \multicolumn{5}{|c|}{ Distress due to craniofacial aggression after accounting for aggression frequency } \\
\hline $\begin{array}{l}\text { Between group } \\
\text { difference in } \\
\text { aggression frequency }\end{array}$ & & & $1.60(0.70-3.64)$ & 0.26 \\
\hline $\begin{array}{l}\text { Between group } \\
\text { difference in } \\
\text { emotional distress }\end{array}$ & & & $1.04(0.92-1.18)$ & 0.53 \\
\hline
\end{tabular}

\footnotetext{
†figures presented are median (IQR).

*using multinomial logistic regression.

IQR = interquartile range (i.e. 25 percentile, 75 percentile).

$\mathrm{OR}=$ odds ratio.

$\mathrm{CI}=$ confidence interval.
} 
of $\mathrm{N} \geqslant 104+m$ ( $m$ being the number of IV's-independent variables) for testing individual predictors. This current study, with 110 cases and four IV's, is likely to be sufficiently powered to detect any clinically relevant differences, and therefore these non-significant results are unlikely to be due to lack of study power.

Relationship of disfigurement severity to frequency of aggression. Using a Kruskal-Wallis test and the full sample $(n=85)$ of young people with craniofacial conditions, no relationship was found between facial disfigurement severity and frequency of physical, verbal or indirect aggression. However, there was a statistically significant relationship between disfigurement severity and frequency of craniofacial aggression, $\chi^{2}(4, n=85)=5.69, p<.05$. Consequently, all combinations of disfigurement severity were compared using Mann-Whitney U tests. Results indicated that the frequency of craniofacial aggression experienced by those with moderate-severe disfigurement differed significantly from that experienced by those with: no disfigurement, $U=9.0, p<.001$; slight disfigurement, $U=129, p<.05$; and slightmoderate disfigurement, $U=138, p<.05$, but did not significantly differ from those with severe disfigurement. Not only does the likelihood of experiencing craniofacial aggression increase with disfigurement severity, but these results also indicate that the frequency of craniofacial aggression increases.

\section{Degree of distress due to aggression}

Multinomial logistic regression was used to test the between group difference in distress resulting from aggression (Table III). Emotional distress, resulting from all 4 types of aggression together, reliably distinguished between groups, $\chi^{2}(4, n=54)=14.142, p<.007$ with approximately $19 \%$ of between group variance accounted for (McFadden's rho $=.19$ ). However, contrary to prediction, young people with and without craniofacial conditions were similarly distressed by physical, verbal and indirect aggression. Only distress due to craniofacial aggression significantly distinguished between groups. However, as shown in Table III, after controlling for frequency of craniofacial aggression, distress due to craniofacial aggression was no longer significant, indicating that the greater distress for those with craniofacial conditions was entirely explained by their experiencing craniofacial aggression more frequently.

\section{Discussion}

To our knowledge, this is the first study comparing the victimization experiences of young people with and without craniofacial conditions using the range of aggression typesphysical, verbal and indirect - that are currently acknowledged in the child development literature, and on 'craniofacial aggression' which covers distressing experiences gleaned from the craniofacial literature such as being stared and pointed at, impersonated, asked personal questions and stood further away from than is usual. Contrary to expectation, no more young people with than without craniofacial conditions were targets of any form of aggression nor experienced more references to their appearance or were more distressed as a result. In fact, fair proportions in both groups were frequently targeted. However, as predicted, those with more severe craniofacial conditions experienced craniofacial aggression more frequently and for that reason experienced more distress. Those with moderate-severe, but not with less or more severe, disfigurement were also most likely to experience frequent verbal aggression. 
The Direct and Indirect Aggression Scale (DIAS), which has been widely used to describe victimization experiences in the general population and was used in this study to compare groups, facilitated a considerably more comprehensive comparative victimization study than the only prior one on those with craniofacial conditions (Broder et al., 2001). However, in original form, it proved to be insensitive to the issues of concern for individuals with craniofacial conditions as none of the three subscales highlights the difference between groups. This problem was somewhat resolved by adding the group of behaviours entitled craniofacial aggression though it is not clear, from this study, whether craniofacial aggression is, in fact, a discrete factor. Resolving this issue would require considerable further research involving greater numbers to facilitate item and factor analysis. Meanwhile, for this preliminary comparative study, craniofacial aggression as a group of behaviours had good face validity as it differentiated those with craniofacial conditions and proved to have sufficient internal reliability to be used as a discrete factor. Using the adapted DIAS, more young people in both groups in this study, compared with others (Rigby, 1996; Walsh, 1998), reported weekly aggression $(26 \%-43 \%$ versus $20-25 \%)$. On review, studies using more questionnaire items appear to result in greater reported incidences of weekly aggression (for examples, see Mooney et al., 1991; Rigby, 1996 and Slee, 1995). This may explain the high incidence of weekly aggression in this study.

This study makes several new contributions to the craniofacial literature. These have implications. The findings that no more young people with, than without, craniofacial conditions are frequent targets of any form of aggression or references to their appearance or suffering resultant distress, and that craniofacial aggression, per se, is no more distressing than physical, verbal or indirect aggression, highlight the fact that young people in the general population also have a problem with victimization. Red hair, freckles, obesity (for possible examples) and the less severe craniofacial disfigurements are, to some extent, similar risks for victimisation. While this may be no consolation to those with craniofacial conditions, it could help put the experience of those with less severe craniofacial disfigurement into greater perspective. A more realistic perspective can be an important cognitive therapy tool. Further, these findings stress that those with craniofacial conditions experience the same broad range of aggressive behaviours as their peers, and not just the particular behaviours identified in the craniofacial literature. Psychosocial interventions to address these issues may therefore be required in order to prevent concomitant distressprimarily depression (Hawker \& Boulton, 2000)—and long-term negative consequences (Roth, Coles \& Heimberg, 2002).

This study confirmed that those with more severe craniofacial disfigurement experience craniofacial aggression more frequently resulting in greater distress. This finding is consistent with similar reports (see Lansdown, Rumsey, Bradbury, Carr \& Partridge, 1997; Kochenderfer Ladd \& Ladd, 2001) and emphasises the positive role that corrective surgery may have in reducing this type of victimization and associated distress. However, this also underscores the limitations of surgery since the majority of young people in this study had undergone some surgical intervention yet more than 40 percent still experienced craniofacial aggression weekly or more. This suggests that 'visibility' remained a problem for them and that they could benefit from further intervention, in addition to surgery, to help them cope with being pointed, stared, laughed, joked and sniggered at, made fun of, impersonated, asked personal questions and having others stand further away from them than is usual. However, we could find no published evaluation of an intervention specifically designed to help young people experiencing craniofacial aggression. We found only two publications evaluating training to deal with others' reactions to disfigurement for adults suffering disfigurement as a result of cancer and other various reasons (Fiegenbaum, 1981; Robinson, 
Rumsey \& Partridge, 1996), some general literature for people with disfigurement (Clarke, 1998, 1999, 2002; Kish \& Lansdown, 2000; Thompson \& Kent, 2001) and one case study of an 'imaginary force field' intervention for young people experiencing verbal aggression (Gerrard, 1991). This indicates that intervention design and evaluation for this population is clearly a necessary research objective.

Of those with craniofacial conditions in the current study, a disproportionately large number with moderate-severe, compared with slight or severe, disfigurement, experienced verbal aggression. There are several possible explanations. Lansdown (1990) and MacGregor et al. (1953) suggest that people with severe disfigurement may ultimately have fewer negative experiences than those with less severe conditions as, being unable to hide their disfigurement and therefore more pressured to accept the reality of it, they may be compelled to develop more helpful interaction skills/strategies. In the current study, it is possible that those with moderate-severe disfigurement were less socially skilled. Alternatively, those with severe disfigurement may have been more socially reclusive hence protected from others' responses, or poorly represented due to low numbers. Further research using a comparatively larger proportion of those with moderate-severe and severe disfigurement is required to clarify the robustness of the current result.

It is of interest to find, in this study, that young people with 'normal' facial figurement also experienced 'craniofacial' aggression, though less frequently. Shute et al. (2002) found that teenage girls intentionally stare at others as a way of conveying dislike and excluding them from the peer group. As a way of minimising their distress, young people with craniofacial conditions are encouraged to consider that people may be staring at them unintentionally as humans are primed to be curious about something new and unexpected in their environment (Changing Faces, 2000). However, it is likely that those with craniofacial conditions experience two qualitatively different forms of staring. This point needs clarifying, as the distinction would inform the content of therapy.

One possible limitation to this study was that only a relatively narrow group of variables was focussed on. No attempt was made to include variables other than disfigurement-such as behaviours - that may also explain victimization experiences. However, having a tightly focussed study was advantageous as it was 'participant friendly' and resulted in an excellent response rate $(68 \%)$ with a population renowned for very low research participation rates. Our results are therefore more likely to generalize to other craniofacial populations. This is an important start in addressing basic questions about victimization for this population.

The main contributions of this study are to provide a basis for social comparison for those who might be prone to interpret social realities in terms of their craniofacial disfigurement and to highlight the limitations of corrective surgery and the need for psychosocial interventions for victimization. For those with a severe disfigurement, surgery may play an important role in reducing some victimization experiences, but this has limitations. It is important for those with craniofacial conditions to know that victimization and references to appearance are also common problems for the general population and that physical, verbal and indirect aggression may be just as distressing for those in the general population as is craniofacial aggression for those with a disfigurement. This information may help promote a more realistic view, not only about their victimization experiences but also about their intervention options.

\section{Acknowledgements}

We gratefully thank all who assisted with this research: the staff and patients of the Australian Craniofacial Unit, the many school Principals and students throughout South 
Australia, Rachel Roberts (Senior Clinical Psychologist for the Australian Craniofacial Unit, Women's and Children's Hospital of South Australia), Tracey Wade (Associate Professor, Flinders University of South Australia) and Kylie Lange (Statistics Consultant, Flinders University of South Australia).

\section{References}

Bjorkqvist, K., Osterman, K., \& Lagerspetz, K. M. J. (1994). Sex differences in covert aggression among adults. Aggressive Behavior, 20, $27-33$.

Bradbury, E. (1996). Counselling people with disfigurement. Leicester: BPS Books.

Broder, H. L., Smith, F. B. \& Strauss, R. P. (2001). Developing a behavior rating for comparing teachers' ratings of children with and without craniofacial anomalies. Cleft Palate-Craniofacial fournal, 38, 560-565.

Cash, T. F. (1995). Developmental teasing about physical appearance: Retrospective descriptions and relationships with body image. Social Behavior E Personality, 23, 123-129.

Changing Faces (2000). Everybody's staring at me: How to communicate when you have an unusual face. London: Changing Faces.

Clarke, A. (1998). 'What happened to your face'? Strategies for managing facial disfigurement. British fournal of Community Nursing, 3, 13-16.

Clarke, A. (1999). Psychosocial aspects of facial disfigurement: problems, management and the role of a lay-led organization. Psychology, Health $\mathcal{G}$ Medicine, 4, 127-142.

Clarke, A. (2002). Managing the psychological aspects of altered appearance: the development of an information resource for people with disfiguring conditions. Patient Education and Counseling, 43, 305-309.

Cohen, J. (1988). Statistical power analysis for behavioral sciences. New York: Academic Press.

Crick, N. R. \& Bigbee, M. A. (1998). Relational and overt forms of peer victimization: a multi-informant approach. fournal of Consulting and Clinical Psychology, 66, 337-347.

Crick, N. R., Nelson, D. A., Morales, J. R., Cullerton-Sen, C., Casas, J. F. \& Hickman, S. E. (2001). Relational victimization in childhood and adolescence: I hurt you through the grapevine. In J. Juvonen \& S. Graham (Eds.), Peer Harassment in School: The Plight of the Vulnerable and Victimized (pp.196-213). New York: The Guilford Press.

Crozier, W. R., \& Dimmock, P. S. (1999). Name-calling and nicknames in a sample of primary school children. British fournal of Educational Psychology, 69, 505-516.

Dawkins, J. (1996). Bullying, physical disability and the paediatric patient. Developmental Medicine $\mathcal{E}$ Child Neurology, 38, 603-612.

Eagly, A. H. \& Steffen, V. J. (1986). Gender and aggressive behaviour: a meta-analytic review of the social psychological literature. Psychological Bulletin, 100, 309-330.

Fiegenbaum, W. (1981). A social skills training program for clients with facial disfigurations: a contribution to the rehabilitation of cancer patients. International fournal of Rehabilitation Research, 4, 501-509.

Gerrard, J. (1991). The teasing syndrome in facially deformed children. Australia and Nerw Zealand fournal of Family Therapy, 12, $147-154$.

Hawker, D. S. J. \& Boulton, M. J. (2000). Twenty years' research on peer victimization and psychosocial maladjustment: a meta-analytic review of cross-sectional studies. Fournal of Child Psychology and Psychiatry, 41, $441-455$.

Keltner, D., Young, R. C., Heerey, E. A., Oemig, C. \& Monarch, N. D. (1998). Teasing in hierachical and intimate relations. Fournal of Personality and Social Psychology, 75, 1231- 1247.

Keltner, D., Capps, L., Kring, A. M., Young, R. C., Heerey, E. A. (2001). Just teasing: a conceptual analysis and empirical review. Psychological Bulletin, 127, 229-248.

Kish, V. (1998b). Do looks count? London: Changing Faces.

Kish, V. (1998c). You're in charge! London: Changing Faces.

Kish, V. \& Lansdown, R. (2000). Meeting the psychosocial impact of facial disfigurement: developing a clinical service for children and families. Clinical Child Psychology and Psychiatry, 5, 497-512.

Kochenderfer Ladd, B. \& Ladd, G. W. (2001). Variations in peer victimization: relations to children's maladjustment. In J. Juvonen \& S. Graham (Eds.), Peer Harassment in School: The Plight of the Vulnerable and Victimized (pp.196-213). The Guilford Press, New York.

Kowalski, R. M. (2000). "I was only kidding!': victims' and perpetrators' perceptions of teasing. Personality and Social Psychology Bulletin, 26, $231-241$.

La Greca, A. M. (1990). Social consequences of pediatric conditions: fertile area for future investigation and intervention? Fournal of Pediatric Psychology, 15, 285-307. 
Lansdown, R. (1990). Psychological problems of patients with cleft lip and palate: discussion paper. fournal of Royal Society of Medicine, 83, 448-450.

Lansdown, R., Rumsey, N., Bradbury, E., Carr, T. \& Partridge, J. (1997). Visibly Different: Coping with disfigurement. Butterworth-Heinemann, Oxford.

Lefebvre, a. \& Munro, I. (1978). The role of psychiatry in a craniofacial team. Psychiatry In Surgery, 61, 564-569.

Lovegrove, E. (2003, January). Teens truant over their looks. BBC NEWS, Education, Wednesday, 8 January, 2003, 11:17 GMT. Retrieved June 4, 2003 from the World Wide Web:http://news.bbc.co.uk/1/hi/education/ 2638337.stm

Macgregor, F. C. (1990). Facial disfigurement: problems and management of social interaction and implications for mental health. Aesthetic Plastic Surgery., 14, 249-257.

MacGregor, F. C., Abel, T. M., Brynt, A., Lauer, E., \& Weissmann, S. (1953). Facial deformities and plastic surgery: A psychosocial study. Charles C. Thomas: Springfield, Illinois.

Marsh, J. L. (1995). Forward. In R. A. Eder (Ed.), Craniofacial Anomalies: Psychological Perspectives (pp. vii-xi). Springer-Verlag, New York.

Mooney, A., Creeser, R. \& Blatchford, P. (1991). Children's view on teasing and fighting in junior schools. . Educational Research, 33, 103-112.

Munro, I. R. (1995). A description of craniofacial anomalies: the mechanism and rationale of surgery. In R. A. Eder (Ed.), Craniofacial Anomalies: Psychological Perspectives (pp. 3-21). Springer-Verlag, New York.

Owens, L. D. (1996). Sticks and stones and sugar and spice: girls' and boys' aggression in schools. . Australian Fournal of Guidance and Counselling, 6, 45-55.

Pallant, J. (2001). SPSS survival manual: a step by step guide to data analysis using SPSS. Allen \& Unwin, Crows Nest, NSW, Australia.

Pawluk, C.J. (1989). Social construction of teasing. Fournal for the Theory of Social Behavior, 19, 145-167.

Richman, L. C. \& Millard, T. (1997). Brief report: Cleft lip and palate: Longitudinal behavior and relationships of cleft conditions to behavior and achievement. Fournal of Pediatric Psychology, 22, 249-257.

Rigby, K. (1996). Bullying in schools: and what to do about it. Camberwell, Victoria: Australian Council for Educational Research (ACER).

Robinson, E., Rumsey, N. \& Partridge, J. (1996). An evaluation of the impact of social interaction skills training for facially disfigured people. British fournal of Plastic Surgery, 49, 281-289.

Roth, D. A., Coles, M. E. \& Heimberg, R. G. (2002). The relationship between memories for childhood teasing and anxiety and depression in adulthood. Anxiety Disorders, 16, 149-164.

Shapiro, J.P., Baumeister, R.F., \& Kessler, J.W. (1991). A three-component model of children's teasing: aggression, humor, and ambiguty. . Fournal of Social and Clinical Psychology, 10, 459-472.

Shaw, W.C., Meeks, S.C. \& Jones, D.S. (1980). Nicknames, teasing, harassment and the salience of dental features among school children. . British fournal of Orthodontics, 7, 75-80.

Shute, R., Owens, L. \& Slee, P. (2002). "You just stare at them and give them daggers": Nonverbal expression of social aggression in teenage girls. International fournal of Adolescence and Youth, 10, 353-372.

Slee, P. T. (1994). Peer victimization and its relationship to depression among Australian primary school students. Fournal of Personality and Individual Differences, 18, 57-62.

Slee, P. T. (1995). Bullying: health concerns of Australian secondary school students. International fournal of Adolescence and Youth, 5, 215-224.

Tabachnick, B. G. \& Fidell, L. S. (1996). Using multivariate statistics (3rd ed.). HarperCollins, New York.

Tan, K. K. \& Pigott, R. W. (1993). A morbidity review of children with complete unilateral cleft lip nose at $10+/-$ years of age. British fournal of Plastic Surgery, 46, 1-6.

Thompson, A. \& Kent, G. (2001). Adjusting to disfigurement: processes involved in dealing with being visibly different. Clinical Psychology Review, 21, 663-682.

Vessey, J. A., Swanson, M. N., \& Hagedorn, M. I. (1995). Teasing: who says names can never hurt you? Pediatric Nursing, 21, 297-302.

Walsh, C. (1998). Peer relationships of adolescents with chronic illness: school absenteeism, perceived peer aggression and loneliness. Unpublished masters thesis. Flinders University, South Australia. 